\title{
Clinical Outcome and Analysis of Total Knee Arthoplasty: A Prospective Study Comparison between Median Parapatellar and Midvastus Approach
}

\author{
Nikhil Sharma ${ }^{1}$, Preetesh Choudhary ${ }^{2}$, D K Taneja ${ }^{3}$ \\ ${ }^{1}$ Post Graduate Trainee (DNB), Department of Orthopedics, Arihant Hospital \& Research Centre, 283- a, Gumasta Nagar, \\ Scheme 71, Indore, Madhya Pradesh 452009, ${ }^{2}$ Associate Professor, Department of Orthopedics, Index Medical College \\ Hospital \& Research Centre, Index City, Nemawar Road, NH-59A, Indore, Madhya Pradesh 452016, ${ }^{3}$ Head of the Department \\ \& Medical Director, Department of Orthopedics \& Traumatology, Arihant Hospital \& Research Centre, 283- a, Gumasta \\ Nagar, Scheme 71, Indore, Madhya Pradesh 452009, India
}

Corresponding author: Dr. Preetesh Choudhary, Associate Professor, Department of Orthopedics, Index Medical College Hospital \& Research Centre, Index City, Nemawar Road, NH-59A, Indore, Madhya Pradesh 452016, India

DOI: http://dx.doi.org/10.21276/ijcmsr.2020.5.1.46

How to cite this article: Nikhil Sharma, Preetesh Choudhary, D K Taneja. Clinical outcome and analysis of total knee arthoplasty: a prospective study comparison between median parapatellar and midvastus approach. International Journal of Contemporary Medicine Surgery and Radiology. 2020;5(1):A211-A218.

\section{A B S T R A C T}

Introduction: Osteoarthritis is being predominantly a mechanical deterioration that might be associated with mal-alignment of the knee. This prospective study was undertaken to compare surgical parameters as well as clinical and radiological outcomes of median parapatellar to midvastus approaches in staged bilateral total knee arthroplasty (TKA).

Material and Methods: In the present study our aim was to assess the results of clinical assessment and analysis with comparison in median parapatellar and midvastus approach in total knee arthroplasty, using Knee Society Knee Score and Function score, Visual Analogue Scale.

Results: In our study pre-operative mean Knee society score in median parapatellar approach was $26.96 \pm 5.29$, while in the mid vastus approach it was $28.84 \pm 6$.49.The postoperative mean knee society score in median parapatellar approach was $50.56 \pm 4.45$, while in the mid vastus approach it was $54.84 \pm 6.19$. At 3 months it was $69.60 \pm 5.93$ in MP approach, while in the mid vastus approach it was $72.60 \pm 4.94$. At 6 months in median parapatellar approach it was $81.76 \pm 5.13$, while in the mid vastus approach it was $84.08 \pm 5.33$. The difference was found to be statistically significant $(p=0.000)$, showing a higher Knee society score at 6 months in comparison to the 3 months and at 3 months compare to 6 weeks which was significant improvement.

Conclusion: The early electro-myographic abnormalities associated with the mid-vastus approach did not result in clinical impairment and they were minimized by blunt dissection within the vastus medialis muscle and it usually resolved. The complete information of the functional innervations of extensor mechanism is important when working with non-traditional approaches in knee arthroplasty. The mid-vastus approach has become our preferred surgical approach for primary total knee arthroplasty.

Keywords: Osteoarthritis, Knee Joint, Total Knee Arthroplasty, Median Parapatellar Approach, Midvastus Approach, Knee Society Knee Score, Function Score, Visual Analogue Scale

\section{INTRODUCTION}

Osteoarthritis of knee is the most common causes of disability in the world, as much as 20 to $40 \%$ in the old age people. ${ }^{1,2,3}$ The chronic rheumatic diseases, hip and knee joint osteoarthritis (OA) is a leading cause of pain and disability in most countries in the world. ${ }^{4}$ Osteoarthritis of the knee results from a wearing away of the articular cartilage of both femur and tibia of the joint. Arthritis might be idiopathic, or it could result from trauma, rheumatoid synovitis, pigmented villonodular synovitis, and seronegative arthropathies such as gout, chondrocalcinosis, osteonecrosis, and idiopathic disorders. $^{4}$
Familial, genetic predisposition may exist, however, and osteoarthritis may result from and be associated with significant synovitis. ${ }^{5}$ Rheumatoid arthritis is being associated with significant synovitis, with $80 \%$ of patients having a positive rheumatoid factor, indicating an autoimmune basis for cartilage destruction. ${ }^{6}$ The knee is the most commonly joint with is affected due to osteoarthritis. Post-traumatic causes include torn menisci, fractures, patellar instability, and loose bodies caused by chondromalacia or synovial chondromatosis. ${ }^{5}$

Mechanical axis variation likevarus or valgus malalignment with obesity may cause abnormal loading of the knee over time and produce premature degeneration of the 
joint cartilage. Infection of the joint causes joint cartilage destruction owing to the proteolytic enzymes released by the leukocytes that enter the knee to combat infection where the enzymes are nonselective in their destructive capabilities. ${ }^{7,8}$ On examination, the patient with arthritis presents initially with stiffness and pain. Characteristically, the patient has stiffness on initiation of gait, which gets better as the knee "warms up. Theremight be an antalgic or painful gait in which the stance phase of the walking cycle is shortened. A knee with varus deformity may demonstrate a lateral thrust due to instability of the lateral collateral ligament and a patient with valgus deformity may show a medial thrust due to an incompetent medial collateral ligament. The survival rate of total knee arthroplasty (TKA) after 10 years has improved to approximately $95 \% .{ }^{9-11}$

The knee might show swelling caused by an effusion and synovitis. Locking might also occur as the bare bony surfaces grate against each other, causing severe pain. Osteophytes may also be palpable on clinical examination. On radiographically, weight-bearing views in AP should be obtained to give the appearance of the knee while it is under stress. A weightbearing view in full extension in standing shows most of the clinical destruction of the joint. TKA with a postoperative mechanical axis of $<3^{\circ}$ of varus or valgus alignment have better long-term survival. ${ }^{12,13}$

Study was done with the aim to compare midvastus approach and median parapatellar approachin terms of pain relief and functional improvement in long term follow up intotal knee arthroplasty and to assess the improvement in parameters were as follows quadriceps function post-operatively, range of movement of the joint and functional score.

Also with the objectives to study the quadriceps functionafter total knee arthroplasty (TKA) by median parapatellar approach versus midvastus approach using knee society score, to assess the functional outcome and blood loss of total knee arthroplasty (TKA) by median parapatellar approach versus midvastus approach clinically and by using knee society knee score, to assess the Patient satisfaction of total knee arthroplasty (TKA) by median parapatellar approach versus midvastus approach and to measure range of movements post-operatively in total knee arthroplasty (TKA) by median parapatellar approach versus midvastus approach using knee society score

\section{MATERIAL AND METHODS}

All confirmed cases of Osteoarthritis in Dept. of Orthopedics in Arihant Hospital \& Research Centre, Indore (M.P.), from June 2017 to June 2019. Cases including either sex will be studied. Patient will be informed about the study in all respects and written informed consent will be obtained. Follow up period was at 6 weeks, 3 months, and 6 months. Institutional Ethical and Scientific Committee of Arihant Hospital and Research Centre, Indore (M.P.) was sought before initiating the study. A voluntary informed consent was taken in writing from every patient/legal guardian, before enrolling any patient in the study.

Inclusion Criteria: Primary osteoarthritis of the knee joint, $\mathrm{BMI}<35$ and patient age above 55 years
Exclusion Criteria: Other inflammatory knee pathology, patients with $\mathrm{BMI}>35$, patients with sepsis of the knee joint, and patients with local skin lesions

Patients included in the study underwent thorough history taking, clinical evaluation and relevant radiological examination. Detailed clinical examination was done to see presence or absence of tenderness, swelling and abnormal mobility in the concerned knee. Passive and active range of motion of affected knee joint was noted. Any flexion deformity or instability in knee was noted pre-operatively. Knee circumference was taken at mid patellar level for all patients preoperatively. Amount of varus / valgus deformity, flexion contracture and range of movements of the joint was noted. Distal neurovascular status of the affected limb was checked. The condition of surrounding soft tissues was also evaluated. The pre-operative pain in visual analogue scale (VAS), Knee Society Score and Functional Knee Score was calculated preoperatively for each patient.

\section{Radiological Assessment}

Radiologically, A/P view (load bearing-standing), lateral views and patella-femoral views were taken. Radiologically following points were emphasized - collateral laxity and subluxation of tibia, presence of osteophytes (femoral, tibial, patellar), quality of bone and bony defects and curvature of the femur and tibia. Medio-lateral and antero-posterior sizing of femoral and tibial component was done.

\section{Surgical Details}

All TKA were done under spinal anesthesia with the patient in supine position and under tourniquet control. After a median longitudinal skin incision had been made, medial parapatellar and midvastus approach was performed in different patients and patellar resurfacing done. After the joint had been exposed, first tibial cut was taken. Before femoral cuts were made, the ligaments were balanced in flexion and extension. After this step, planning for the femoral cut was done. Balancing of flexion and extension gaps, femoral rotation and femoral joint inclination, the size of the prosthesis and its best positioning could be defined, always in relation to the mechanical axis. After the femoral and tibial cuts had been made, the respective trial components were tested, and the quality of the limb alignment in relation to the mechanical axis in the coronal and sagittal planes and adequacy of the balancing for the planned implants were again investigated. All the components were then placed appropriately and cemented. Thoroughly wash was given and Ranawat orthopaedic centre cocktail was used for post-operative pain, closure done layer by layer. The data were duly recorded and subsequently compared in order to produce this study. All the operations were performed by the different surgeons. Patient was discharged on $3^{\text {rd }}$ post-op day and physiotherapy was started as knee flexion extension from the same day (day of operation) and from next-day full weight bearing with walker support and knee strengthening exercises were started. Suture removal was done on 15 th postoperative day.

\section{RESULTS}

The table 1 shows the distribution of patients according to 
age in both medial parapatellar approach and mid vastus approach groups. In median parapatellar approach, 1 (4.0\%) patient was in the age group 35-40 years, 1 (4.0\%) patient was in the age group 41-50 years, $6(24.0 \%)$ patients were in the age group 51-60 years, $13(52.0 \%)$ patients were in the

\begin{tabular}{|c|c|c|c|c|}
\hline \multirow[t]{2}{*}{ Age } & \multicolumn{2}{|c|}{$\begin{array}{c}\text { Median Parapatellar } \\
\text { Approach }\end{array}$} & \multicolumn{2}{|c|}{$\begin{array}{l}\text { Mid Vastus } \\
\text { Approach }\end{array}$} \\
\hline & No. & $\%$ & No. & $\%$ \\
\hline $35-40$ years & 1 & 4.0 & 0 & 0.0 \\
\hline $41-50$ years & 1 & 4.0 & 1 & 4.0 \\
\hline $51-60$ years & 6 & 24.0 & 3 & 12.0 \\
\hline $61-70$ years & 13 & 52.0 & 14 & 56.0 \\
\hline $71-80$ years & 4 & 16.0 & 7 & 28.0 \\
\hline Total & 25 & 100.0 & 25 & 100.0 \\
\hline Mean \pm SD (Age) & \multicolumn{2}{|c|}{$63.68 \pm 9.40$} & \multicolumn{2}{|c|}{$66.32 \pm 7.37$} \\
\hline \multicolumn{5}{|l|}{ Sex } \\
\hline Female & 13 & 52.0 & 13 & 52.0 \\
\hline Male & 12 & 48.0 & 12 & 48.0 \\
\hline Total & 25 & 100.0 & 25 & 100.0 \\
\hline
\end{tabular}

Unpaired ' $\mathrm{t}$ ' test applied. P value $<0.05$ was taken as statistically significant

Table-1: Distribution of patients according to age \& sex $(\mathrm{N}=50)$

\begin{tabular}{|l|c|c|c|c|}
\hline \multirow{2}{*}{ Adverse Events } & \multicolumn{2}{|c|}{$\begin{array}{c}\text { Median } \\
\text { Parapatellar } \\
\text { Approach }\end{array}$} & \multicolumn{2}{|c|}{$\begin{array}{c}\text { Mid Vastus } \\
\text { Approach }\end{array}$} \\
\cline { 2 - 5 } & No. & $\%$ & No. & $\%$ \\
\hline No adverse events & 21 & 84.0 & 24 & 96.0 \\
\hline $\begin{array}{l}\text { Breathlessness for short } \\
\text { duration }\end{array}$ & 1 & 4.0 & 0 & 0.0 \\
\hline Moderate pain in night & 1 & 4.0 & 0 & 0.0 \\
\hline Painful movements & 1 & 4.0 & 0 & 0.0 \\
\hline Soakage present & 0 & 0.0 & 1 & 4.0 \\
\hline Spinal headache & 1 & 4.0 & 0 & 0.0 \\
\hline Total & 25 & 100.0 & 25 & 100.0 \\
\hline Table- Distibution of patients & & & & \\
\hline
\end{tabular}

Table-2: Distribution of patients according to adverse events $(\mathrm{N}=50)$ age group 61-70 years and $4(16.0 \%)$ patients were in the age group 71-80 years. In mid vastus approach, 1 (4.0\%) patient was in the age group 41-50 years, $3(12.0 \%)$ patients were in the age group 51-60 years, $14(56.0 \%)$ patients were in the age group $61-70$ years and $7(28.0 \%)$ patients were in the age group 71-80 years.

The mean age in median parapatellar approach was 63.68 \pm 9.40 years and in the mid vastus approach it was $66.32 \pm$ 7.37 years. The difference was found to be statistically not significant $(p=0.275)$, showing that the mean age in both the groups was comparable. In both median parapatellar approach and mid vastus approach, there were 13 (52.0\%) females and 12 (48.0\%) males, showing a comparable distribution of patients in relation to sex in both the groups, with a female preponderance in the study [Table 1].

The table 2 shows the distribution of patients according to adverse events in both medial parapatellar approach and mid vastus approach groups. In median parapatellar approach, in $21(84.0 \%)$ patients no adverse events were seen. In 1 (4.0\%) patient breathlessness of short duration was seen, 1 (4.0\%) patient had moderate pain in night, 1 (4.0\%) patient had painful movements and 1 (4.0\%) patient had spinal headache. In mid vastus approach, in 24 (96.0\%) patients no adverse events were seen. In $1(4.0 \%)$ patient soakage was present. In both the groups, major adverse events were not encountered, but in median parapatellar approach, more number of patients experienced adverse events in comparison to the mid vastus approach patients.

The table 3 shows the comparison of mean function score between medial parapatellar approach and mid vastus approach groups at different time intervals.

Preoperative: The mean function score in median parapatellar approach was $20.60 \pm 5.65$, while in the mid vastus approach it was $21.04 \pm 7.15$. The difference was found to be statistically not significant $(\mathrm{p}=0.810)$, showing a comparable mean function score between vastus approach and median parapatellar approach.

At 6 weeks: The mean function score in median parapatellar approach was $40.80 \pm 5.34$, while in the mid vastus approach

\begin{tabular}{|l|c|c|c|c|}
\hline Time Interval & $\begin{array}{c}\text { Median Parapatellar } \\
\text { Approach [Mean } \pm \text { SD] }\end{array}$ & $\begin{array}{c}\text { Mid Vastus Approach } \\
{[\text { Mean } \pm \text { SD] }}\end{array}$ & ' $t$ ' value & P value \\
\hline Preoperative & $20.60 \pm 5.65$ & $21.04 \pm 7.15$ & $-0.241, \mathrm{df}=48$ & $0.810, \mathrm{NS}$ \\
\hline 6 weeks & $40.80 \pm 5.34$ & $45.00 \pm 6.77$ & $-2.436, \mathrm{df}=48$ & $0.019^{*}$ \\
\hline 3 months & $59.40 \pm 5.07$ & $64.80 \pm 7.43$ & $-3.003, \mathrm{df}=48$ & $0.004^{*}$ \\
\hline 6 months & $80.40 \pm 4.98$ & $84.80 \pm 4.89$ & $-3.151, \mathrm{df}=48$ & $0.003^{*}$ \\
\hline Unpaired 't' test applied. P value < 0.05 was taken as statistically significant \\
\hline \multicolumn{2}{|r}{ Table 3: Comparison of mean function score between the two groups at different time intervals (N=50) } \\
\hline
\end{tabular}

\begin{tabular}{|l|c|c|c|c|}
\hline Time Interval & $\begin{array}{c}\text { Median Parapatellar } \\
\text { Approach [Mean } \pm \text { SD] }\end{array}$ & $\begin{array}{c}\text { Mid Vastus Approach } \\
{[\text { Mean } \pm \text { SD] }}\end{array}$ & ' $t$ ' value & P value \\
\hline Preoperative & $26.96 \pm 5.29$ & $28.84 \pm 6.49$ & $-1.121, \mathrm{df}=48$ & $0.268, \mathrm{NS}$ \\
\hline 6 weeks & $50.56 \pm 4.45$ & $54.84 \pm 6.19$ & $-2.806, \mathrm{df}=48$ & $0.007^{*}$ \\
\hline 3 months & $69.60 \pm 5.93$ & $72.60 \pm 4.94$ & $-1.943, \mathrm{df}=48$ & $0.058, \mathrm{NS}$ \\
\hline 6 months & $81.76 \pm 5.13$ & $84.08 \pm 5.33$ & $-1.569, \mathrm{df}=48$ & $0.123, \mathrm{NS}$ \\
\hline Unpaired 't' test applied. P value $<0.05$ was taken as statistically significant \\
\hline \multicolumn{4}{|l}{ Table 4: Comparison of mean Knee Society score between the two groups at different time intervals (N=50) } \\
\hline
\end{tabular}


it was $45.00 \pm 6.77$. The difference was found to be statistically significant $(p=0.019)$, showing a higher function score in the mid vastus approach in comparison to the median parapatellar approach.

At 3 months: The mean function score in median parapatellar approach was $59.40 \pm 5.07$, while in the mid vastus approach it was $64.80 \pm 7.43$. The difference was found to be statistically significant $(p=0.004)$, showing a higher function score in the mid vastus approach in comparison to the median parapatellar approach.

At 6 months: The mean function score in median parapatellar approach was $80.40 \pm 4.98$, while in the mid vastus approach it was $84.80 \pm 4.89$. The difference was found to be statistically significant $(\mathrm{p}=0.003)$, showing a higher function score in the mid vastus approach in comparison to the median parapatellar approach. The mean function score was statistically significantly higher in mid vastus approach in comparison to the median parapatellar approach at all the time intervals.

The table 4 shows the comparison of mean Knee society

\begin{tabular}{|c|c|c|c|}
\hline Time Interval & $\begin{array}{c}\text { Median } \\
\text { Parapatellar } \\
\text { Approach } \\
{[\text { Mean } \pm S D]}\end{array}$ & 't' value & $P$ value \\
\hline Preoperative & $20.60 \pm 5.65$ & \multirow[t]{2}{*}{$-17.785, d f=24$} & \multirow[t]{2}{*}{$0.000 *$} \\
\hline 6 weeks & $40.80 \pm 5.34$ & & \\
\hline 6 weeks & $40.80 \pm 5.34$ & \multirow[t]{2}{*}{$-16.909, \mathrm{df}=24$} & \multirow[t]{2}{*}{$0.000 *$} \\
\hline 3 months & $59.40 \pm 5.07$ & & \\
\hline 3 months & $59.40 \pm 5.07$ & \multirow[t]{2}{*}{$-24.249, \mathrm{df}=24$} & \multirow[t]{2}{*}{$0.000 *$} \\
\hline 6 months & $80.40 \pm 4.98$ & & \\
\hline
\end{tabular}

Paired ' $\mathrm{t}$ ' test applied. $\mathrm{P}$ value $<0.05$ was taken as statistically significant

Table-5: Comparison of mean function score between various time intervals in the median parapatellar approach group $(\mathrm{N}=25)$

\begin{tabular}{|c|c|c|c|}
\hline Time Interval & $\begin{array}{l}\text { Mid vastus } \\
\text { Approach } \\
{[\text { Mean } \pm \text { SD] }}\end{array}$ & 't' value & $P$ value \\
\hline Preoperative & $21.04 \pm 7.15$ & \multirow[t]{2}{*}{$-16.488, d f=24$} & \multirow[t]{2}{*}{$0.000 *$} \\
\hline 6 weeks & $45.00 \pm 6.77$ & & \\
\hline 6 weeks & $45.00 \pm 6.77$ & \multirow[t]{2}{*}{$-18.681, d f=24$} & \multirow[t]{2}{*}{$0.000^{*}$} \\
\hline 3 months & $64.80 \pm 7.43$ & & \\
\hline 3 months & $64.80 \pm 7.43$ & \multirow[t]{2}{*}{$-16.803, d f=24$} & \multirow[t]{2}{*}{$0.000 *$} \\
\hline 6 months & $84.80 \pm 4.89$ & & \\
\hline \multicolumn{4}{|c|}{$\begin{array}{l}\text { Paired ' } \mathrm{t} \text { ' test applied. P value }<0.05 \text { was taken as statistically } \\
\text { significant }\end{array}$} \\
\hline \multicolumn{4}{|c|}{$\begin{array}{l}\text { Table-6: Comparison of mean function score between various } \\
\text { time intervals in the mid vastus approach group }(\mathrm{N}=25)\end{array}$} \\
\hline
\end{tabular}

score between medial parapatellar approach and mid vastus approach groups at different time intervals.

Preoperative: The mean Knee society score in median parapatellar approach was $26.96 \pm 5.29$, while in the mid vastus approach it was $28.84 \pm 6.49$. The difference was found to be statistically not significant $(p=0.268)$, showing a comparable Knee society score between mid vastus approach and median parapatellar approach.

At 6 weeks: The mean Knee society score in median parapatellar approach was $50.56 \pm 4.45$, while in the mid vastus approach it was $54.84 \pm 6.19$. The difference was found to be statistically significant $(p=0.007)$, showing a higher Knee society score in the mid vastus approach in comparison to the median parapatellar approach.

At 3 months: The mean Knee society score in median parapatellar approach was $69.60 \pm 5.93$, while in the mid vastus approach it was $72.60 \pm 4.94$. The difference was found to be statistically not significant $(p=0.058)$, showing a comparable Knee society score.

At 6 months: The mean Knee society score in median parapatellar approach was $81.76 \pm 5.13$, while in the mid vastus approach it was $84.08 \pm 5.33$. The difference was found to be statistically not significant $(p=0.123)$, showing a comparable Knee society score.

The table 5 shows the comparison of mean function score between various time intervals in the median parapatellar approach group. The mean preoperative function score was $20.60 \pm 5.65$, while at 6 weeks it was $40.80 \pm 5.34$. The difference was found to be statistically significant $(p=0.000)$, showing a higher function score at 6 weeks in comparison to the preoperative time.

The mean function score at 6 weeks was $40.80 \pm 5.34$, while at 3 months it was $59.40 \pm 5.07$. The difference was found to be statistically significant $(\mathrm{p}=0.000)$, showing a higher function score at 3 months in comparison to the 6 weeks. The mean function score at 3 months was $59.40 \pm 5.07$, while at 6 months it was $80.40 \pm 4.98$. The difference was found to be statistically significant $(\mathrm{p}=0.000)$, showing a higher function score at 6 months in comparison to the 3 months. Thus, there was a statistically significant improvement in the mean function score at each follow-up in the median parapatellar group.

The table 6 shows the comparison of mean function score between various time intervals in the mid vastus approach group. The mean preoperative function score was $21.04 \pm$ 7.15 , while at 6 weeks it was $45.00 \pm 6.77$. The difference was found to be statistically significant $(p=0.000)$, showing a higher function score at 6 weeks in comparison to the preoperative time.

The mean function score at 6 weeks was $45.00 \pm 6.77$, while

\begin{tabular}{|l|c|c|c|c|}
\hline Parameter & $\begin{array}{c}\text { Median Parapatellar } \\
\text { Approach } \\
{[\text { Mean } \pm \text { SD] }}\end{array}$ & $\begin{array}{c}\text { Mid Vastus Approach } \\
{[\text { Mean } \pm \text { SD] }}\end{array}$ & ' 't' value & P value \\
\hline Pain score & $2.36 \pm 0.99$ & $1.48 \pm 0.87$ & $3.326, \mathrm{df}=48$ & $0.002^{*}$ \\
\hline Unpaired 't' test applied. P value < 0.05 was taken as statistically significant \\
\hline \multicolumn{2}{|r|}{ Table-7: Comparison of mean pain score between the two groups at different time intervals ( $\mathrm{N}=50)$} \\
\hline
\end{tabular}


at 3 months it was $64.80 \pm 7.43$. The difference was found to be statistically significant $(\mathrm{p}=0.000)$, showing a higher function score at 3 months in comparison to the 6 weeks. The mean function score at 3 months was $64.80 \pm 7.43$, while at 6 months it was $84.80 \pm 4.89$. The difference was found to be statistically significant $(\mathrm{p}=0.000)$, showing a higher function score at 6 months in comparison to the 3 months. Thus, there was a statistically significant improvement in the mean function score at each follow-up in the mid vastus group.

The mean intraoperative blood loss in median parapatellar approach was $258.00 \pm 40.00 \mathrm{ml}$, while in the mid vastus approach was $180.00 \pm 45.64 \mathrm{ml}$. The difference was found to be statistically significant $(p=0.000)$, showing a higher intraoperative blood loss in the median parapatellar approach in comparison to the mid vastus approach.

The table 7 shows the comparison of mean pain score between medial parapatellar approach and mid vastus approach groups. The mean pain score in median parapatellar approach was $2.36 \pm 0.99$, while in the mid vastus approach it was $1.48 \pm 0.87$. The difference was found to be statistically significant $(p=0.000)$, showing a higher pain score in the median parapatellar approach in comparison to the mid vastus approach.

\section{DISCUSSION}

In osteoarthritic knee non-operative modalities like physical therapy, lifestyle changes, medications provide benefits for small duration. Surgical options include arthroscopic debridement, proximal tibial osteotomy or proximal fibular osteotomy, and uni-compartmental and total knee replacement. ${ }^{14}$ Total knee arthroplasty is very effective procedure and associated with substantial improvement in function. Old age patients found better relief with the total knee arthroplasty surgery rather than conservative management which leads to relief in joints pain,increase range of movement, correction of deformity and improvement in the quality of life while doing daily activities. ${ }^{15}$

The median para-patellar approach is the most commonly utilized approach for primary TKR. However it disturbs the medial to lateral balance of extensor mechanism and leads to patellar maltracking and fracture. Lateral retinacular release has been utilized to improve patellar tracking but it may be accompanied by wound complication and compromise of patellar vascularity and increasing the chance of osteonecrosis or loosening. ${ }^{16}$

In our study the mean age in median parapatellar approach was 65.36 years and in the midvastus approach it was 67.16 years, in a study Lizaur et al (1984) it was 68.3 years which correlates our study. ${ }^{17}$ This is also comparable to the study age group in the meta analysis of Hetaimish et al (69.0 $)^{18}$ and studies of Sparmann et al (67.4) ${ }^{19}$ and Kim et al (67.6). ${ }^{20}$ This denotes that the most of the osteoarthritis patient in this particular age group are present in India and also ready for TKA surgery.

A female preponderance in the current study ( $\mathrm{m}: \mathrm{f}=24: 26)$ amounting to $52 \%$ of all patients correlates well with numerous studies which also show a higher incidence of osteoarthritis in female gender. However in our study there is not a big difference. High gender ratio in knee arthritis due to menopause is a possible cause for the skew in the number of patients towards females. The other important cause particularly to the Indian population is use of squatting position in household work and activities of daily living in both genders. Hame et al (2013) ${ }^{21}$ had shown that women are more severely impacted by knee osteoarthritis. O'Connor et al $(2007)^{22}$ had also shown the female preponderance in osteoarthritis of knee joint. However, in our study we have applied this Knee Society Knee Score as a benchmarking tool for comparing between knee society score rating system was an outgrowth of the hospital for special surgery rating system. Pre-and post-operative results of median parapatellar and mid-vastus approach in TKA. On statistical analysis, Knee Scores showed significant improvement on 6 weeks, 3 and 6 months,

\begin{tabular}{|l|c|c|}
\hline Duration & $\begin{array}{c}\text { Mean knee } \\
\text { society knee } \\
\text { score (out of } \\
\text { 100) in median } \\
\text { para-patellar } \\
\text { approach }\end{array}$ & $\begin{array}{c}\text { Mean knee } \\
\text { society knee } \\
\text { score (out } \\
\text { of 100) in } \\
\text { mid-vastus } \\
\text { approach }\end{array}$ \\
\hline Pre-operative & 26.96 & 28.84 \\
\hline Post-operative 6 weeks & 50.56 & 54.84 \\
\hline Post-operative 3 month & 69.60 & 72.60 \\
\hline Post-operative 6 month & 81.76 & 84.08 \\
\hline
\end{tabular}

While comparing the pre-operative knee scores with various studies available in literature, Pang et al (2009) ${ }^{23}$ reported that pre-op knee scores of 32.90 in a study of 35 patients. Luzo et al $(2014)^{24}$ in a study of 200 patients reported the pre-operative KSS at a mean of 44.13. Lutzner et al (2008) $)^{25}$ studied 40 patients with navigation TKA and reported a preoperative knee score at 36.50. The mean Knee society score in our study in median parapatellar approach was 26.96, while in the mid vastus approach it was 28.84. So our study also comparable to other studies in knee society score. ${ }^{23-25}$

\begin{tabular}{|c|c|c|c|}
\hline Duration & $\begin{array}{l}\text { Mean } \\
\text { Knee } \\
\text { Society } \\
\text { Function } \\
\text { Scores } \\
\text { (out of } \\
\text { 100) In } \\
\text { our study } \\
\text { (median } \\
\text { parapa- } \\
\text { tellar } \\
\text { approach) } \\
\mathrm{N}=\mathbf{2 5}\end{array}$ & $\begin{array}{l}\text { Mean } \\
\text { Knee } \\
\text { Society } \\
\text { Function } \\
\text { Scores } \\
\text { (out of } \\
100 \text { ) in } \\
\text { our study } \\
\text { (mid-vas- } \\
\text { tus ap- } \\
\text { proach) } \\
\mathrm{N}=\mathbf{2 5}\end{array}$ & $\begin{array}{c}\text { Study } \\
\text { by } \\
\text { Luzo } \\
\text { et al }{ }^{24} \\
\mathrm{~N}=200\end{array}$ \\
\hline Pre-operative & 26.96 & 28.84 & 44.13 \\
\hline 6 weeks post-operative & 50.56 & 54.84 & - \\
\hline 3 months post-operative & 69.60 & 72.60 & - \\
\hline 6 months post-operative & 81.76 & 84.08 & 76.85 \\
\hline
\end{tabular}

Pre-operative function score in our study is20.60in medianparapatellar approach and 21.04 in mid-vastus approach. Pang et $\mathrm{al}^{23}$ in their study report a function score Preoperatively at 39.10 in study of 35 patients. Lutzner et $\mathrm{al}^{25}$ studied 40 patients with navigation TKA and reported a pre-operative function score at 52.50. So in our study the pre-op function score is less comparable to these studies, 
the reason behind that may be patient appeared late or took late decision for TKA. Kelly et al $(2006)^{26}$ in their study of 51 knee with randomized to treatment with a median parapatellar or mid-vastus approach and it report hospital for special surgery mean score was 47.5 at pre-op and 71.5 at 5 years post-op in mid-vastus approach and it was 40.42 at pre-op and 69.26 at 5 years post-op in median-para-patellar approach. $^{23,24}$

Keating et al (2006) ${ }^{27}$ study, a total of 100 patients undergoing bilateral simultaneous total knee replacements were randomized prospectively to receive a mid-vastus muscle-splitting approach on one side and modified median parapatellar approach on the other side and show there is less terminal extension in median-parapatellar (59 independently) and in midvastus (66 independently). At discharge extension lag was more in median-parapatellar $\left(2.97^{\circ}\right)$ than mid-vastus $\left(2.47^{\circ}\right) .^{27}$

Pre-operative antibiotics were given prior the surgery. All the surgeries were done in operation theatre as per the protocol of replacement surgeries. Bryan et al $(1984)^{28}$ had reported significance decrease in infection rate when replacement surgeries done after giving prior antibiotics. Wilson et al $(1990)^{29}$ also gave the same results as per given by Bryan. Lidwell et al (1986) shown that there is combined effect of laminar airflow and prophylactic antibiotics. ${ }^{30}$

In our study the mean intraoperative blood loss in median parapatellar approach was $258.00 \mathrm{ml}$, while in the mid vastus approach was $180.00 \mathrm{ml}$. Kelly et al $(2006)^{26}$ in their study there was estimated blood loss was $129.6 \mathrm{ml}$ in Mid-vastus and $200 \mathrm{ml}$ in median-parapatellar approach. Avci et al $(2013)^{31}$ reported that there is less blood loss in mid-vastus approach compare to median para-patellar approach.

\begin{tabular}{|l|c|c|}
\hline Study & $\begin{array}{c}\text { Mean } \\
\text { intra-oper- } \\
\text { ative blood } \\
\text { loss(in } \\
\text { ml) in our } \\
\text { study }\end{array}$ & $\begin{array}{c}\text { Mean } \\
\text { intra-oper- } \\
\text { ative blood } \\
\text { loss (in ml) } \\
\text { in study by } \\
\text { Matthew } \\
\text { et al }\end{array}$ \\
\hline Median para-patellar approach & $258(\mathrm{n}=25)$ & $200(\mathrm{n}=29)$ \\
\hline Mid-vastus approach & $180(\mathrm{n}=25)$ & $129.6(\mathrm{n}=22)$ \\
\hline $\mathrm{n}$ - number of knees operated & \\
\hline
\end{tabular}

In our study, in median para-patellar approach there was adverse events occur like one patient had spinal headache which corrected next day, one patient had complaint of shortness of breath as patient was above the age of 70 , the pre-op saturation was also less compare to normal and preop physician fitness was also taken for every patient. One patient experienced severe pain at night, so epidural infusion was continue given to the patient upto the next day. In one mid-vastus approach patient soakage was present daily for 2-3 days because intra-op blood less was very less in the patient so we didn't apply the Romovac drain (we use to apply in every patient) and soakage persist for 3 days.

In our study no case of infection were noted. Two patients had serous discharge in median para-patellar approach, in these patients we took the decision for debridement and opened the knees again and serous discharge sample was sent for examination and found no infection. The both patients were too fatty, so fat necrosis may be the cause of discharge as the patients were overweight, after irrigation and debridement no discharge were found in both patient. Due to this discharge their Range of movement recovery affected so progression was delayed but later at 9 months of follow up range of movements were excellent.

One patient in our study in median para-patellar approach effusion was present after discharge from the hospital. Aspiration of the fluid was done and found no infective pathology. After 2 times of aspiration it didn't appear again but the patient also had delayed in recovery of range of movements. In our study a gradual, but progress is noticed throughout, viz., pre-operative, one month, three month, six month stage. The study was co-related with the study of Luzo et al at six months post-operative stage. ${ }^{24}$

\begin{tabular}{|l|c|c|c|}
\hline Grading (out of 100) & $\begin{array}{c}\text { \% of } \\
\text { patients in } \\
\text { our study. } \\
\mathbf{N = 2 5} \\
\text { (6 months } \\
\text { post-op) in } \\
\text { median pa- } \\
\text { ra-pateller } \\
\text { approach }\end{array}$ & $\begin{array}{c}\text { \% of pa- } \\
\text { tients in our } \\
\text { study. } \mathbf{N}=\mathbf{2 5} \\
\text { (6 months } \\
\text { post-op) in } \\
\text { mid-vastus } \\
\text { approach }\end{array}$ & $\begin{array}{c}\text { Luzo et } \\
\text { a }^{24} \text { study. } \\
\mathbf{N = 2 0 0} \\
\text { (6 months } \\
\text { post-op) }\end{array}$ \\
\hline Excellent (>84) & 40 & 68 & 37.8 \\
\hline Good (70-84) & 60 & 32 & 39.8 \\
\hline Insufficient (60-69) & 0 & 0 & 12.8 \\
\hline Poor (<60) & 0 & 0 & 9.7 \\
\hline
\end{tabular}

A comparison between our study and Luzo et $\mathrm{al}^{24}$, reveals excellent scores in our case is $68 \%$ in midvastus approach and $40 \%$ in median-parapatellar approach while in Luzo et al study it show $37.8 \%$ patients reported excellent functional KSS. The percentage is comparable and mid-vastus approach patient has better results than compare to median parapatellar approach in early post-op period. ${ }^{24}$ In our study, median parapatellar approach patient had some complication like serous discharge, knee effusion so grading effected and leads to delay in the recovery period. In some obese and most severe OA knee patient we elected the median para-patellar approach so ROM compare to pre-op was excellent but overall it's in good grading.

In our study the overall excellent outcome in median parapatellar group was lower than that of mid-vastus approach group. The reason is being that more complicated cases (osteoarthritis) were managed using median parapatellar approach. Very few studies are present where VAS has been used for evaluating post-operative pain in TKA patients The mean pain score in median parapatellar approach was 2.36, while in the mid vastus approach it was 1.48 . This shows that patients in mid-vastus approach presented at a slightly better pain relief than median para-patellar approach.

Successful functional outcome of TKA also depend on the post-op physiotherapy. In our patients we started physiotherapy from the next day of surgery with full weight bearing and upto $90^{\circ}$ knee ROM were done and the same protocol was applied for both median para-patellar and midvastus approach and we also found that the active SLR and ROM were less in median para-ptellar approach compare to mid-vastus approach. Avci et al (2013) ${ }^{31}$ and Keating et al 
$(2006)^{27}$ study also show the same result with less knee ROM and active SLR in median para-patellar approach compare to mid-vastus approach.

\section{CONCLUSION}

We conclude that mid-vastus approach for primary total knee arthroplasty compares favourably with the traditional median para-patellar approach in the early period of followup. The Range of movement, active straight leg raise test were better in mid vastus approach post-op compare to median para-patellar approach in early post-operative period. However upto 9 months of follow up both type of patients with different approach gained the same range of movement. The intra-op blood loss was also less in mid vastus approach. Surgical duration is almost equal in both approaches.

The early electro-myographic abnormalities associated with the mid-vastus approach did not result in clinical impairment and they were minimized by blunt dissection within the vastus medialis muscle and it usually resolved. The complete information of the functional innervations of extensor mechanism is important when working with non-traditional approaches in knee arthroplasty. The mid-vastus approach has become our preferred surgical approach for primary total knee arthroplasty.

\section{REFERENCES}

1. Felson DT. Epidemiology of hip and knee osteoarthritis. Epidemiol Rev. 1988; 10(3):1-28.

2. Cross M, Smith E, Hoy D, Nolte S, Ackerman I, Fransen M, et al. The global burden of hip and knee osteoarthritis: estimates from the global burden of disease 2010 study. Ann Rheum Dis. 2014; 73(1):132330.

3. Pal CP, Singh P, Chaturvedi S, Pruthi KK, Vij A. Epidemiology of knee osteoarthritis in India and related factors. Indian J Orthop. 2016;50(5):518-522.

4. Dorr LD, Boiardo RA. Technical considerations in total knee arthroplasty. Clin Orthop Relat Res. 1986; 205(4):5-11.

5. Loeser RF, Goldring SR, Scanzello CR, Goldring MB. Osteoarthritis: a disease of the joint as an organ. Arthritis Rheum. 2012;64(6):1697-1707.

6. Guo Q, Wang Y, Xu D, Nossent J, Pavlos NJ, Xu J. Rheumatoid arthritis: pathological mechanisms and modern pharmacologic therapies. Bone Res. 2018;6(5):15.

7. Kane RL, Saleh KJ, Wilt TJ, Bershadsky B, Cross WW, MacDonald RM, Rutks I. Total knee arthroplasty. Evid Rep Technol Assess (Summ) 2003; 86(1):1-8.

8. Delp SL, Stulberg SD, Davies B, Picard F, Leitner F. Computer assisted knee arthroplasty. Clin Orthop Relat Res. 1998; 354(3):49-56.

9. Knutson K, Lindstrand A, Lidgren L. Survival of knee arthroplasties. A nation-wide multicentre investigation of 8000 cases.J Bone Joint Surg Br. 1986;68(1):795-803.

10. Laskin RS. The Genesis total knee prosthesis: a 10-year follow-up study. Clin Orthop Relat Res. 2001;388(5):95-102.

11. Rodriguez JA, Bhende H, Ranawat CS. Total condylar knee replacement: a 20-year follow-up study. Clin
Orthop Relat Res. 2001;388(4):10-7.

12. Lotke PA, Ecker ML. Influence of positioning of prosthesis in total knee replacement. J Bone Joint Surg Am. 1977;59(3):77-9.

13. Bargren JH, Blaha JD, Freeman MA. Alignment in total knee arthroplasty. Correlated biomechanical and clinical observations.Clin Orthop Relat Res. 1983;173(6):17883.

14. Rönn K, Reischl N, Gautier E, Jacobi M. Current surgical treatment of knee osteoarthritis. Arthritis. 2011;2011:454873.

15. Lee JK, Choi CH. Total knee arthroplasty in rheumatoid arthritis. Knee Surg Relat Res. 2012;24(1):1-6.

16. Maniar RN, Singhi T, Rathi SS, Baviskar JV, Nayak RM. Surgical technique: Lateral retinaculum release in knee arthroplasty using a stepwise, outside-in technique. Clin Orthop Relat Res. 2012; 470(10):2854-2863.

17. Lizaur A, Marco L, Cebrian R. Preoperative factors influencing the range of movement after total knee arthroplasty for severe osteoarthritis. J Bone Joint Surg Br. 1997;79(4):626-9.

18. Hetaimish BM, Khan MM, Simunovic N, Al-Harbi $\mathrm{HH}$, Bhandari M, Zalzal PK. Meta-Analysis of Navigation vs Conventional Total Knee Arthroplasty. J Arthroplasty. 2012; 27(6):1177-82.

19. Sparmann M, Wolke B, Czupalla H, Banzer D, Zink A. Positioning of total knee arthroplasty with and without navigation support. J Bone Joint Surg Br. 2003; 85(1):830-5.

20. Kim YH, Kim JS, Yoon SH. Alignment and orientation of the components in total knee replacement with and without navigation support. J Bone Joint Surg $[\mathrm{Br}]$ 2007;89-B:471-6.

21. Hame SL, Alexander RA. Knee osteoarthritis in women. Curr Rev Musculoskelet Med. 2013;6(2):182-7.

22. O'Çonnor MI. Sex difference in osteoarthritis of the hip and knee.J Am Acad Orthop Surg. 2007;15 Suppl 1:S22-5.

23. Pang $\mathrm{CH}$, Chan WL, Yen $\mathrm{CH}$, Cheng $\mathrm{SC}$, Woo SB, Choi ST, et al. Comparison of total knee arthroplasty using computer-assisted navigation versus conventional guiding systems: a prospective study. J Orthop Surg (Hong Kong). 2009;17(2):170-3.

24. Luzo MVM, Ambra LFM, Debieux P, Franciozi CES, Costi RR, Petrilli MT, et al. Artroplastia total do joelhoauxiliada por navegac, ão: análise de 200 casos. Rev Bras Ortop. 2014; 49(1):149-53.

25. Lützner J, Krummenauer F, Wolf C, Günther KP, Kirschner S. Computer-assisted and conventional total knee replacement. J Bone Joint Surg [Br] 2008;90B:1039-44

26. Kelly MJ, Rumi MN, Kothari M, Parentis MA, Bailey KJ, Parrish WM, Pellegrini VD Jr. Comparison of the vastus-splitting and median parapatellar approaches for primary total knee arthroplasty: a prospective, randomized study. J Bone Joint Surg Am. 2006;88(4):715-20.

27. Keating EM, Faris PM, Meding JB, Ritter MA. Comparison of the midvastus muscle-splitting approach with the median parapatellar approach in total knee arthroplasty. J Arthroplasty. 1999;14(1):29-32. 
28. Bryan WJ, Ranawat CS, Rose HA. Replacement of the patella-femoral joint with the total condylar knee arthroplasty. Int Orthop. 1984;8(1):61-5.

29. Wilson MG, Kelley K, Thornhill TS. Infection as a complication of total knee replacement arthroplasty: risk factors and treatment in sixty-seven cases. J Bone Joint Surg Am. 1990;72(6):878-83.

30. Lidwell OM.Clean air at operation and subsequentsepsis in the joint. Clin Orthop Relat Res. 1986;(211):91-102.

31. Avci CC,Gulabi D,Erdem M, Kurnaz R, Gunes T, Bostan B. Minimal invasive midvastus versus parapatellar approach in total knee arthroplasty.Acta Orthop Traumatol Turc. 2013;47(1):1-7.

Source of Support: Nil; Conflict of Interest: None

Submitted: 22-01-2020; Accepted: 11-02-2020; Published online: 20-03-2020 